\title{
SESMIC RESPONSE OF R.C. BUILDING FRAMES WITH STRAP FOOTING CONSIDERING SOIL STRUCTURE INTERACTION
}

\author{
M. G. Kalyanshetti ${ }^{1}$, S. A. Halkude ${ }^{2}$, Y. C. Mhamane ${ }^{3}$ \\ Civil Engineering. Department,. Walchand Institute of Technology, Solapur, Solapur University, India \\ Imgkalyanshetti@gmail.com, ${ }^{2}$ halkude60@gmail.com, 3yogitamhamane@gmail.com
}

\begin{abstract}
In the conventional design practice the buildings are assumed to be fixed at their bases even though they are supported on flexible media (soil) which will change the structural behaviour. Thus to evaluate the realistic behavior of structure the soil structure interaction (SSI) effect shall be incorporated in the analysis. In the present study two SSI models are considered for the analysis; one is replacing soil by spring of equivalent stiffness (Discrete Support) and second by considering the whole soil mass beneath footing (Elastic Continuum). The support flexibility causes differential settlements and rotations of footings which lead to redistribution of forces/moments in the members of the structure. It possible to control these effects by providing the strap beam in the footing. Therefore in the present study an attempt is also made to investigate the influence of strap footing to control the SSI effect. The study is carried on 3D building frame of different story heights supported on soft soil. The seismic analysis is carried out using equivalent static method as per IS 1893-2002. The influence of SSI on various seismic parameters and the flexural parameters are presented. The changes in all these parameters due to provision of strap footing is studied in order to evaluate it's effectiveness in controlling the SSI effect. The study reveals that the SSI significantly alters the forces/ moments in the members of the structure which is possible to control effectively by providing the strap footing.
\end{abstract}

Keywords: Soil Structure Interaction, Equivalent Static Method, Elastic Continuum Method, Spring method, Strap Footing. $* * *$

\section{INTRODUCTION:}

The process in which the response of the soil influences the motion of the structure and the motion of the structure influences the response of the soil is termed as SoilStructure Interaction (SSI). Present study attempts to learn the effect of SSI on various response parameters of building frames. Many researchers have proposed different methods to evaluate the effect of SSI. Winkler's idealization (1867) represents the soil medium as a system of identical but mutually independent, closely spaced, discrete, linearly elastic springs. Using this idealization Federal Emergency Management Agency (FEMA) ${ }^{[1]}$ (1991) has presented complete set of algebraic formulas and dimensionless charts for readily computing the dynamic stiffness (K) and damping coefficient (c) of foundation.

In the elastic continuum approach it is possible to consider the whole influenced soil mass beneath the footing with high degree of realism including nonlinear stress-strain behaviour, non-homogenous material condition, and change in geometry etc. B.R. Jayalaxmi et al ${ }^{[4]}$ (2009) studied earthquake response of multi-storeyed RC frame with soil structure interaction effects by modelling structure foundation-soil system using Finite Element Method. It is observed that seismic response of buildings considering SSI exhibit variation based on frequency content of motion and stiffness of soil. Garg and Hora ${ }^{[5]}$ (2012) analyzed the performance of frame-footing-soil system by considering plane frame, infill frame, homogenous soil and layered soil mass. They concluded that shear force and bending moment in superstructure get significantly altered due to differential settlement of soil mass. It is also concluded that inclusion of strap beams in the foundation will prevent failure/ distress of the structure likely to be caused by redistribution of moments / forces due to SSI effect.

\section{OBJECTIVE OF THE STUDY:}

The objective of the present study is

1) To investigate the SSI effect on various response parameters of the building frames by discrete support (using spring) and Elastic Continuum (using FEM) method to study the effectiveness and utility of these approaches.

2) To evaluate the effectiveness of introduction of strap beam in the footings to counterbalance the SSI effect

\section{SSI MODELS:-}

In the present study two SSI models are considered. In one of the model, soil mass is idealized as Spring of equivalent stiffness, generally known as Winkler's idealization and another is Elastic Continuum Model where the whole soil mass in the influence zone beneath the footing is considered. The details regarding these models are given below.

\subsection{Winkler model (Spring Model):}

Effect of soil flexibility is incorporated by considering equivalent springs with $6 \mathrm{DOF}$ as shown in Figure 1. The stiffness along these 6 DOF is determined as per FEMA. These are shown in Table1. 


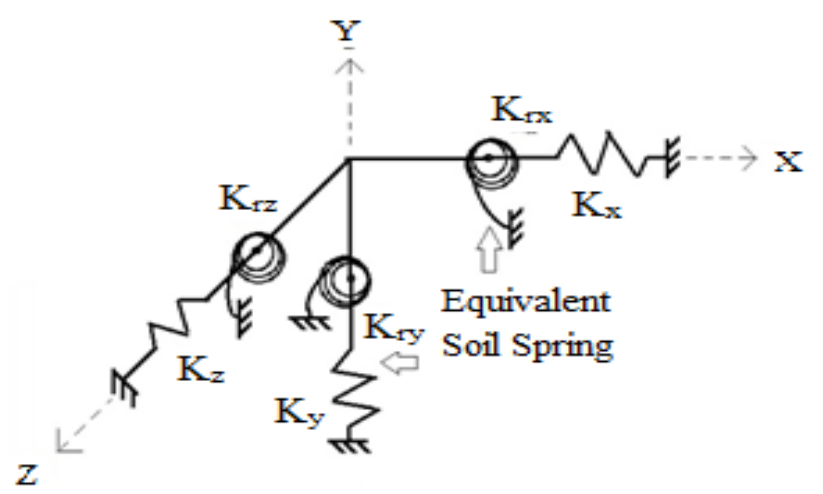

Fig 1:- Equivalent soil spring stiffness along 6 degrees of freedom

Table 1:-Stiffness Equations for Surface Foundation (FEMA 356)

\begin{tabular}{|l|l|}
\hline Degree of Freedom & Spring Stiffness \\
\hline Translation along X-axis & $K_{x, \text { sur }}=\frac{G B}{2-\mu}\left[3.4\left(\frac{L}{B}\right)^{0.65}+1.2\right]$ \\
\hline Translation along Y-axis & $K_{y, \text { sur }}=\frac{G B}{2-\mu}\left[3.4\left(\frac{L}{B}\right)^{0.65}+0.4\left(\frac{L}{B}\right)+0.8\right]$ \\
\hline Translation along Z-axis & $K_{z, \text { sur }}=\frac{G B}{1-\mu}\left[1.55\left(\frac{L}{B}\right)^{0.75}+0.8\right]$ \\
\hline Rocking about X-axis & $K_{x x, s u r}=\frac{G B^{s}}{1-\mu}\left[0.4\left(\frac{L}{B}\right)+0.1\right]$ \\
\hline Rocking about Y-axis & $K_{y y, s u r}=\frac{G B^{s}}{1-\mu}\left[0.47\left(\frac{L}{B}\right)^{2.4}+0.034\right]$ \\
\hline Torsion about Z-axis & $K_{z z, s u r}=G B^{3}\left[0.53\left(\frac{L}{B}\right)^{2.45}+0.51\right]$ \\
\hline
\end{tabular}

\subsection{Elastic Continuum Model (ECM):-}

In this idealization the whole soil mass in the influence zone beneath the footing is considered as a elastic continuum. The finite soil mass is considered based on convergence study, with boundary beyond which soil mass is not influenced by structural loading. This is assumed to be at a lateral offset of width of the building on all four sides and depth equal to 1.5 times the width of building.

\subsection{FEM Formulation:-}

\section{A) Soil Mass}

The soil mass below the foundation is discretized as eight noded solid elements with $3 \mathrm{DOF}$ at each node. This will help to create the continuity and compatibility in stress and strain in all 3 directions. This will assist in more precise evaluation of stress and strain in soil mass. The soil mass is assumed to be linear, elastic and isotropic.

\section{B) Frame Elements}

The beams and columns are modeled as frame element with 2 nodes. The element has 6 DOF at each node. Translation in $\mathrm{X}, \mathrm{Y}, \mathrm{Z}$ direction and rotations @ X, Y, Z axis. It is a uniaxial element with tension, compression and bending capabilities.

\section{C) Foundation}

The foundation is discretized as eight noded brick element. The foundation material is assumed to be elastic and isotropic. The element is defined by eight nodes, thickness, and the material properties.

\section{D) Slab}

Slab is modeled as plate element. A plate is a planer structure with a very small thickness in comparison to the planer dimensions. It has four corner nodes with three degrees of freedom $\left(\mathrm{u}_{\mathrm{z}}, \theta_{\mathrm{x}}, \theta_{\mathrm{y}}\right)$ at each node. The above mentioned elements are shown in Table 2.The typical spring model and elastic continuum model are shown in Figure 2. 
Table 2:-Different Element used in the FEM formulation

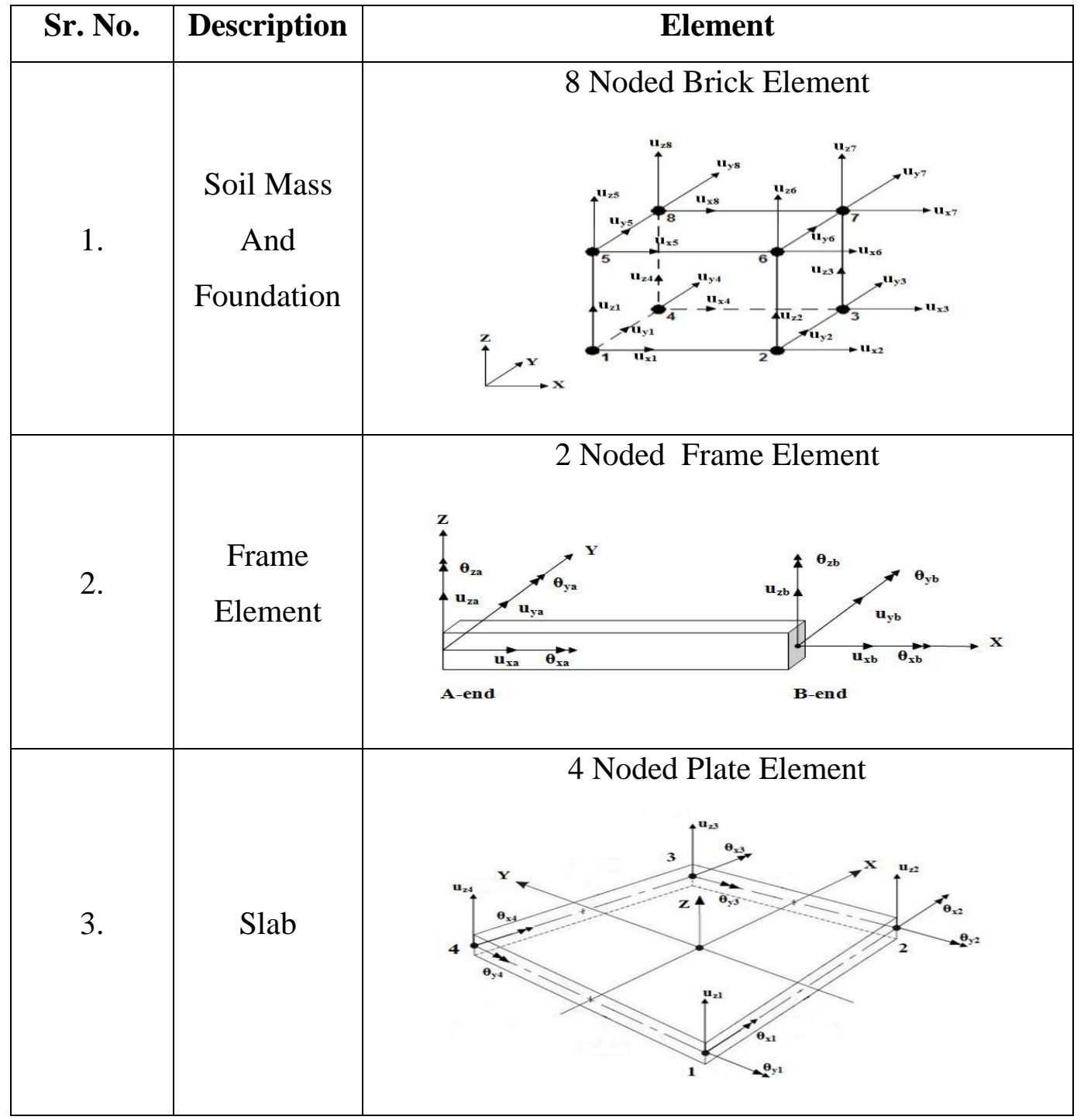

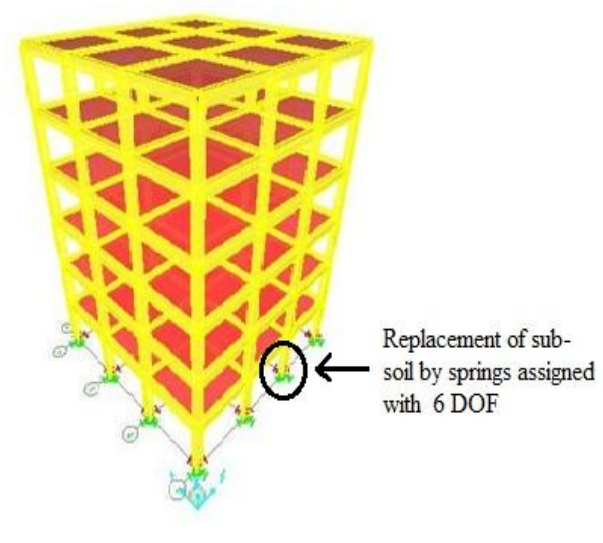

(a) Spring model

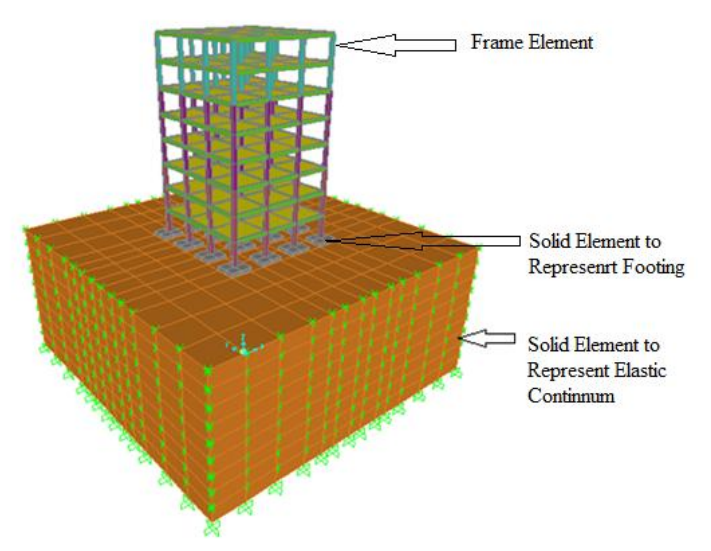

(b) Elastic continuum model

Fig. 2:- SSI models 


\section{PARAMETRIC STUDY:-}

Symmetric building space frames in plan of $\mathrm{G}+5, \mathrm{G}+7, \mathrm{G}+10$ and $\mathrm{G}+12$ are considered to be resting on soft soil. The Modulus of elasticity (Es) and Poisson's ratio $(\mu)$ is considered as $15000 \mathrm{kN} / \mathrm{m}^{2}$ and 0.4 respectively as per Bowel ${ }^{[6]}$. The unit weight is assumed as $16 \mathrm{kN} / \mathrm{m}^{3}$. The details of the building frames are given in Table 3.The seismic analysis is carried out in accordance with IS:1893-2002 using structural software SAP-2002

Table 3:- Building Frame Details

\begin{tabular}{|c|c|c|c|c|c|}
\hline \multicolumn{6}{|c|}{ DIMENSIONS OF COMPONENTS OF BUILDING } \\
\hline $\begin{array}{l}\text { Bldg. } \\
\text { Frame }\end{array}$ & Description & $\begin{array}{l}\text { Column } \\
(\mathbf{m} \mathbf{X} \mathbf{m})\end{array}$ & $\begin{array}{c}\text { Beam } \\
(\mathbf{m} \text { X m) }\end{array}$ & $\begin{array}{l}\text { Footing size } \\
(\mathbf{L x} \text { B x T) }\end{array}$ & $\begin{array}{c}\text { Slab } \\
\text { Thickness } \\
\text { (m) }\end{array}$ \\
\hline \multirow[t]{2}{*}{$\mathrm{G}+5$} & For 4-6 storey & $0.30 \times 0.40$ & $0.30 \times 0.45$ & \multirow[t]{2}{*}{$\begin{array}{c}1.90 \mathrm{X} 2.05 \mathrm{X} \\
0.45\end{array}$} & 0.15 \\
\hline & Up to 3 storey & $0.30 \times 0.45$ & $0.30 \times 0.45$ & & 0.15 \\
\hline \multirow{3}{*}{$\mathrm{G}+7$} & For $7-8$ storey & $0.30 \times 0.40$ & $0.30 \times 0.45$ & \multirow{3}{*}{$\begin{array}{c}2.15 \times 2.35 \mathrm{X} \\
0.5\end{array}$} & 0.15 \\
\hline & For 4-6 storey & $0.30 \times 0.45$ & $0.30 \times 0.45$ & & 0.15 \\
\hline & Up to 3 storey & $0.30 \times 0.50$ & $0.30 \times 0.45$ & & 0.15 \\
\hline \multirow{3}{*}{$\mathrm{G}+10$} & For 9-11 storey & $0.30 \times 0.40$ & $0.30 \times 0.45$ & \multirow{3}{*}{$\begin{array}{c}2.55 \times 2.75 \mathrm{X} \\
0.6\end{array}$} & 0.15 \\
\hline & For 5-8 storey & $0.30 \times 0.45$ & $0.30 \times 0.45$ & & 0.15 \\
\hline & Up to 4 storey & $0.30 \times 0.50$ & $0.30 \times 0.45$ & & 0.15 \\
\hline \multirow{4}{*}{$\mathrm{G}+12$} & For 11-13 storey & $0.30 \times 0.40$ & $0.30 \times 0.45$ & \multirow{4}{*}{$3 \times 2.8 \times 0.8$} & 0.15 \\
\hline & For $8-10$ storey & $0.30 \times 0.45$ & $0.30 \times 0.45$ & & 0.15 \\
\hline & For $4-7$ storey & $0.30 \times 0.50$ & $0.30 \times 0.45$ & & 0.15 \\
\hline & Up to 3 storey & $0.30 \times 0.55$ & $0.30 \times 0.45$ & & 0.15 \\
\hline
\end{tabular}

Effects of SSI on various seismic parameters i.e. Natural Time Period, Roof Displacement, Base Shear and various flexural parameter i.e. Beam bending moment, Beam shear force are studied. The results corresponding to both SSI models (flexible base condition) are compared with the results of conventional analysis (fixed base condition) to investigate their effectiveness.

Effects of support flexibility, corresponding to both SSI models for various parameters are presented below;

\subsection{Natural Time Period:-}

The variation in Natural Time Period of structure of various height and various base conditions are presented in Figure 3.

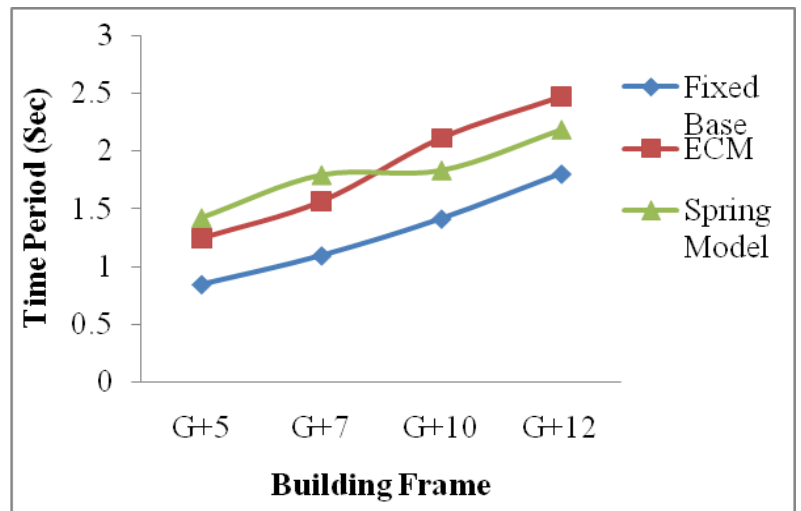

Fig. 3:-Variation of Natural Time Period for different support conditions

It is observed from Figure 3 that for a given base condition time period increases with increase in no of storey. This trend is observed for all base condition. However for spring model the increase in time period from $G+7$ to $G+10$ is negligibly small. 
For a building frame with given no of storey the time period is found to be minimum for fixed base condition. The time period increases with the change in base condition from fix to flexible. Initially for low storey buildings the spring model predicts high time period in comparison with Elastic continuum model. However with increasing no of storey the pattern is observed to be reversing.

It is also observed that in spring model the percentage increase in time period is in the range of $21 \%$ for low storey buildings which increases to $39 \%$ with increase in no of storey. In the elastic continuum model it ranges from $37 \%$ for low storey buildings to $47 \%$ for high storey building. This shows that Elastic continuum model shows higher values.

\subsection{Roof Displacement:-}

The variations for Roof Displacement are presented in Figure 4.

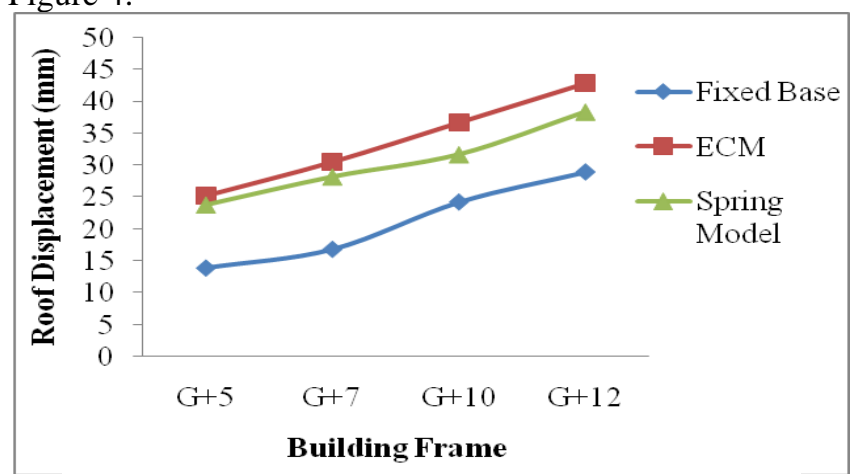

Fig. 4:- Variation of Roof Displacement for different support conditions

It is observed from figure 4 that for a given base condition the Roof Displacement goes on increasing with increase in no of storey. Elastic continuum model is predicting the higher roof displacement than spring model for higher no of storey. In spring model the increase in roof displacement in comparison with fixed base is in the range of 32 to $40 \%$ from $\mathrm{G}+5$ to $\mathrm{G}+12$ frames respectively whereas in the elastic continuum model it is in the range of 34 to $55 \%$. Upto G+7 roof displacement is almost same for both the SSI models. However Elastic continuum model shows higher values for $G+10$ and $G+12$ building frames. This shows that for high rise buildings the elastic continuum model is effective showing higher values which is more realistic.

\subsection{Base Shear:-}

The variations for Base Shear is presented in Figure 5.

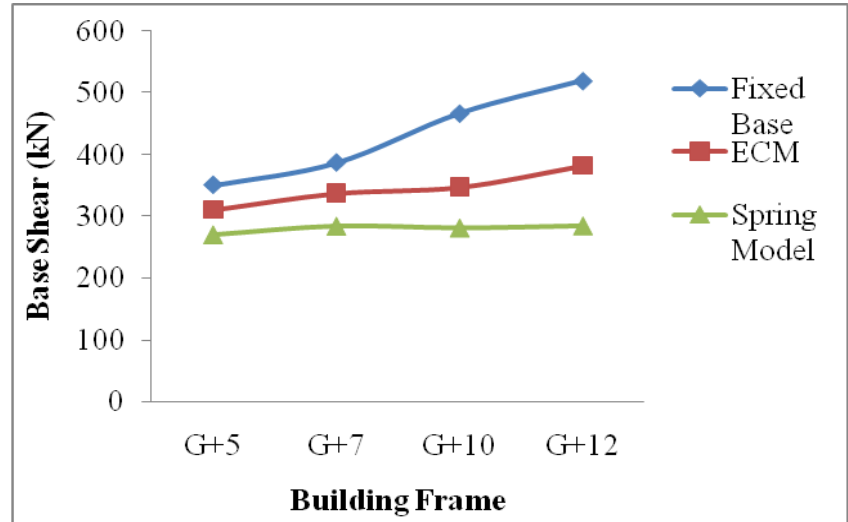

Fig. 5:-Variation of Base Shear for different support conditions

It is observed from figure 5 that for fixed base condition the base shear is observed to be maximum which increases with increase in no of storey with steeper rate. However for spring model which has produced least base shear there is not much variation in the base shear with increasing no of storey.

In the elastic continuum model the percentage decrease in base shear is in the range of 11 to $26 \%$ in comparison with fixed base whereas in spring model it is in the range of 22 to $45 \%$.

\subsection{Beam Moment:-}

The variations for Beam Moment are presented in Figure 6.

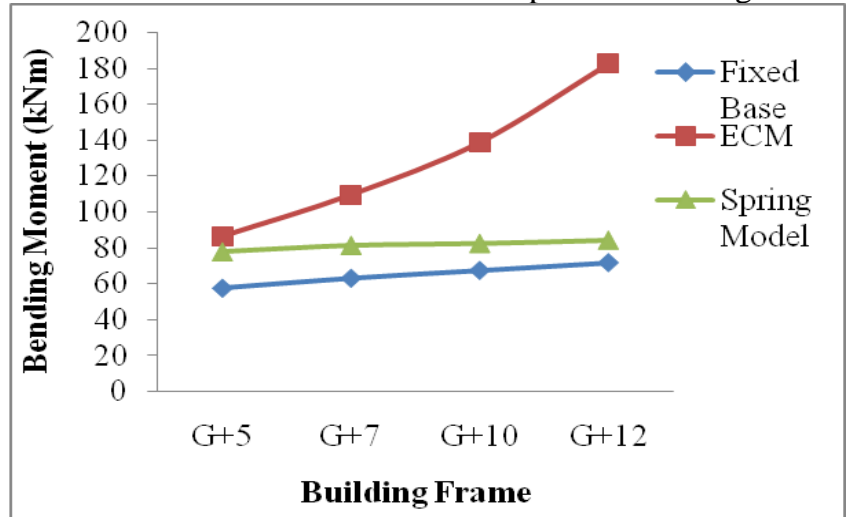

Fig. 6:- Variation of Bending Moment for different support conditions

Figure 6 shows that bending moment for flexible base is higher than fixed base condition. In spring model the increase in bending moment is from $17 \%$ for $\mathrm{G}+5$ frame to $34 \%$ for $\mathrm{G}+12$ frame in comparison with fixed base whereas in the elastic continuum model the increase is from $50 \%$ for $\mathrm{G}+5$ to $154 \%$ for $\mathrm{G}+10$ frame. The increase is with steeper rate for high story buildings. Thus it is revealed that SSI significantly increases the bending moment in high rise buildings. Elastic continuum model is more effective as it reflects the flexibility of soil beneath the footing more realistically as compared to spring model. 


\subsection{Beam Shear Force:-}

The variations for beam shear force is presented in Figure 7.

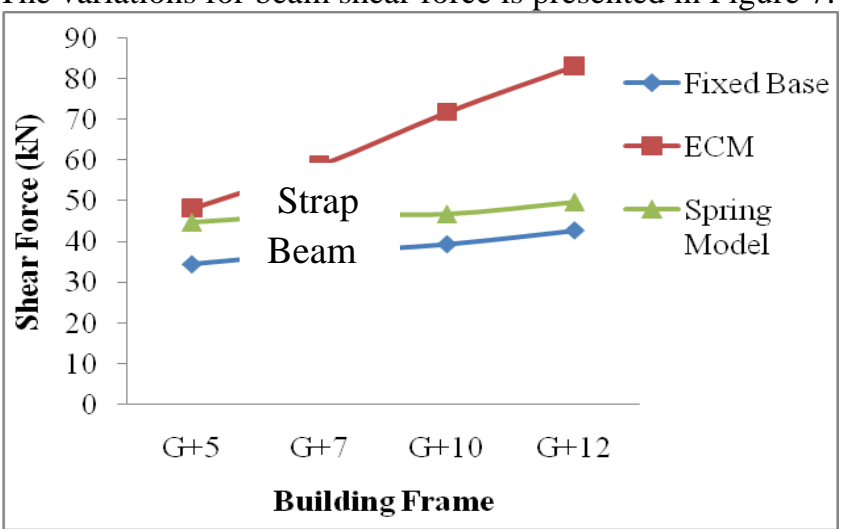

Figure 7:- Variation of Shear Force for different support conditions

It is observed from figure 7 that shear force for flexible base is higher than fixed base condition.

In spring model the increase in shear force is from $16 \%$ for $\mathrm{G}+5$ frame to $29 \%$ for $\mathrm{G}+10$ frame in comparison with fixed base whereas in the elastic continuum model the increase is from $39 \%$ for $\mathrm{G}+5$ frame to $94 \%$ for $\mathrm{G}+10$ frame. The increase is with steeper rate for high rise buildings. The shear force increases with higher rate in Elastic continuum model as compared to spring model wherein variation is marginal. Thus it is revealed that elastic continuum model is more effective as it reflects the flexibility of soil beneath the footing more realistically as compared to spring model.

\section{EFFECTIVENESS OF STRAP FOOTING TO}

\section{CONTROL SSI EFFECT:-}

The strap beams plays important role in SSI by providing good control on the rotations of the footings within permissible limits caused due to support flexibility. Strap beam increases the stiffness of column at base which is beneficial to counterbalance SSI effect. Hence the study is carried out to evaluate the effectiveness of strap beam to control SSI effect. The sizes of the strap beam for the different building frame under consideration are taken as $0.45 \mathrm{~m} \mathrm{X} 0.45 \mathrm{~m}$ for $\mathrm{G}+5,0.5 \mathrm{~m} \times 0.55 \mathrm{~m}$ for $\mathrm{G}+7,0.5 \mathrm{~m} \mathrm{X}$ $0.65 \mathrm{~m}$ for $\mathrm{G}+10$ and $0.55 \mathrm{~m}$ X0.73m for $\mathrm{G}+12$ building. The strap beams are provided along the peripheral as shown in figure 8 .
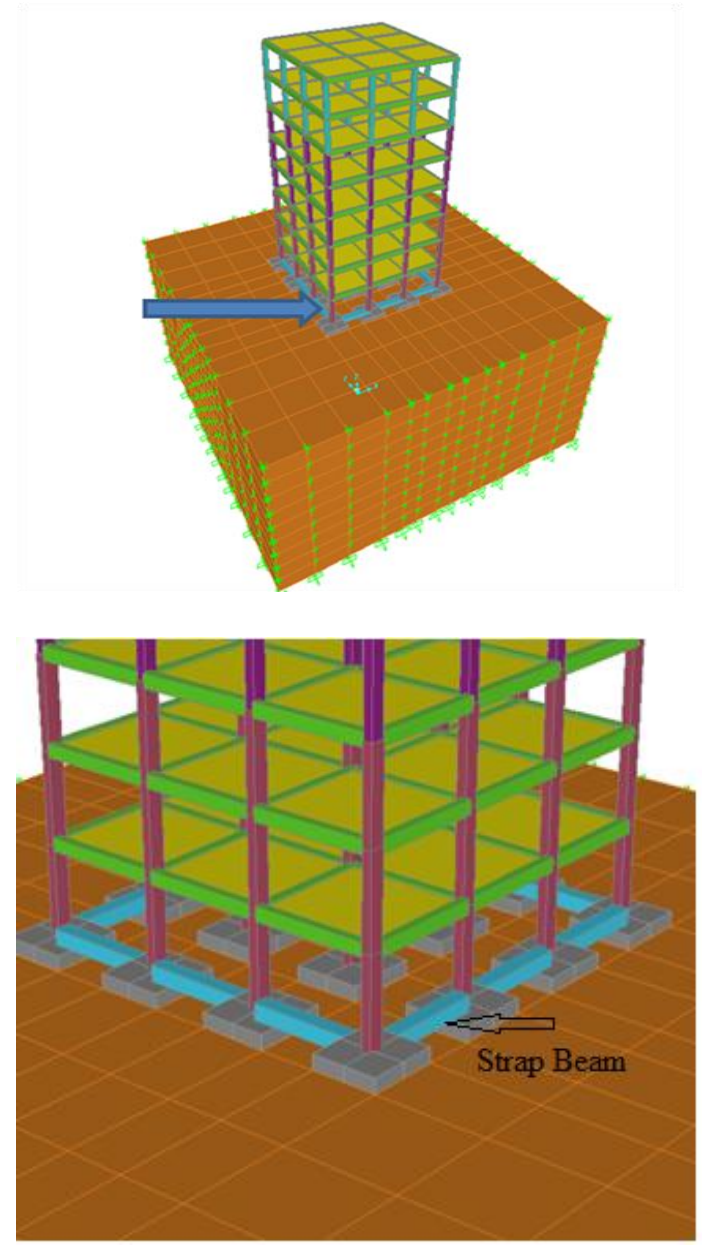

Fig. 8:- Typical Building Frame with Strap Footing

From the previous section it is observed that SSI is more effectively simulated in the elastic continuum model. Therefore the further study is carried out by introducing strap beam in the elastic continuum model and it's effectiveness on different response parameters are also presented and discussed below ;

\subsection{Natural Time Period:-}

The variation in Natural Time Period of structure is presented in Figure 9.

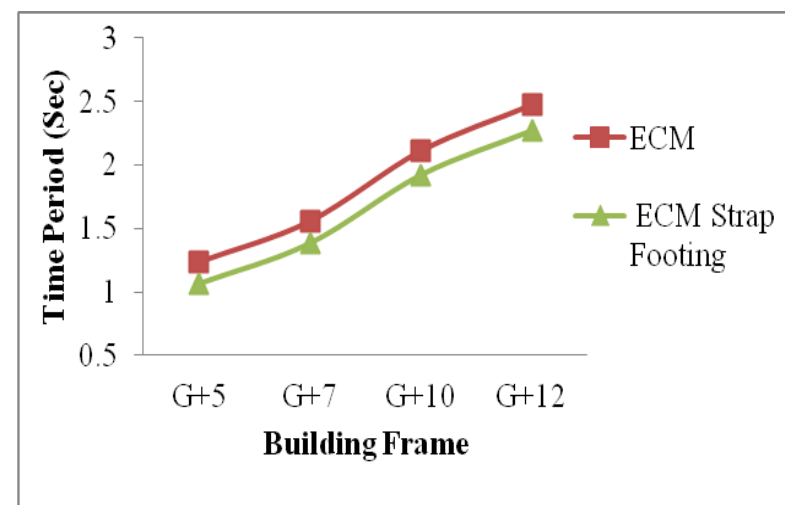

Fig. 9:- Variation of Natural Time Period incorporating Strap Footing 
From Figure 9 it is observed that introduction of strap beam at base has reduced the time period thus counterbalancing the SSI effect. The percentage reduction in time period is $21 \%, 16 \%, 13 \%$ and $11 \%$ for $\mathrm{G}+5, \mathrm{G}+7, \mathrm{G}+10$ and $\mathrm{G}+12$ building frame, respectively with respect to flexible base. Thus study reveals that strap beam effect is more prominent in case of low story building as compared to high story building as percentage reduction in time period is higher for low story buildings.

\subsection{Roof Displacement:-}

The variations for Roof Displacement are presented in Figure 10.

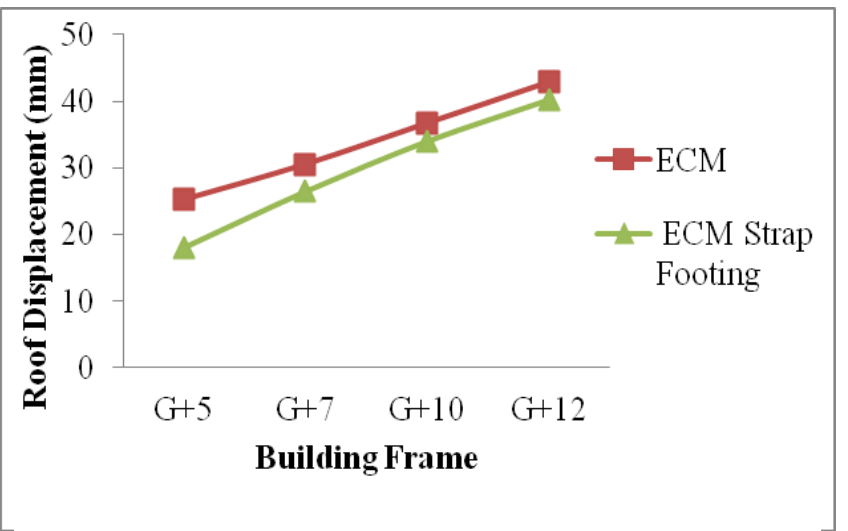

Fig. 10:-Variation of Roof Displacement incorporating Strap Footing

From Figure 10 it is observed that introduction of strap at base has reduced the roof displacement thus counterbalancing the SSI effect. For G+5, G+7, G+10 and $\mathrm{G}+12$ building frame, the percentage reduction in roof displacement is $51 \%, 23 \%, 11 \%$ and $9 \%$ respectively with respect to flexible base. Thus study reveals that strap beam effect is more prominent in case of low story building as compared to high story building as percentage reduction in roof displacement is considerably higher for low story buildings.

\subsection{Base Shear:-}

The variations for Base Shear are presented in Figure11.

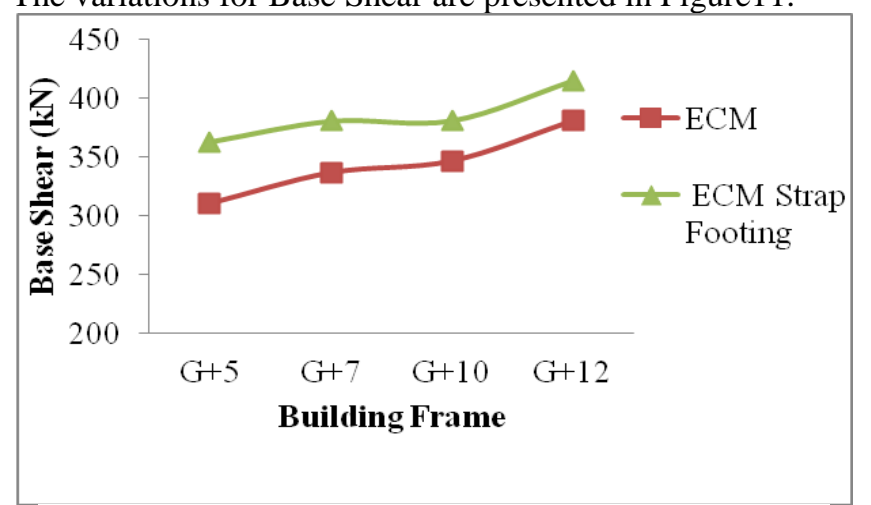

Fig. 11:- Variation of Base Shear incorporating Strap Footing

From Figure 11 it is observed that introduction of strap at base has increased the base shear counterbalancing the SSI effect. For $\mathrm{G}+5, \mathrm{G}+7, \mathrm{G}+10$ and $\mathrm{G}+12$ building frame, the percentage increase in Base Shear is $12 \%, 10 \%, 7 \%$ and $6 \%$ respectively with respect to flexible base. Thus study reveals that strap beam effect is more prominent in case of low story building as compared to high story buildings.

\subsection{Beam Moment:-}

The variations for Beam Moment are presented in Figure12.

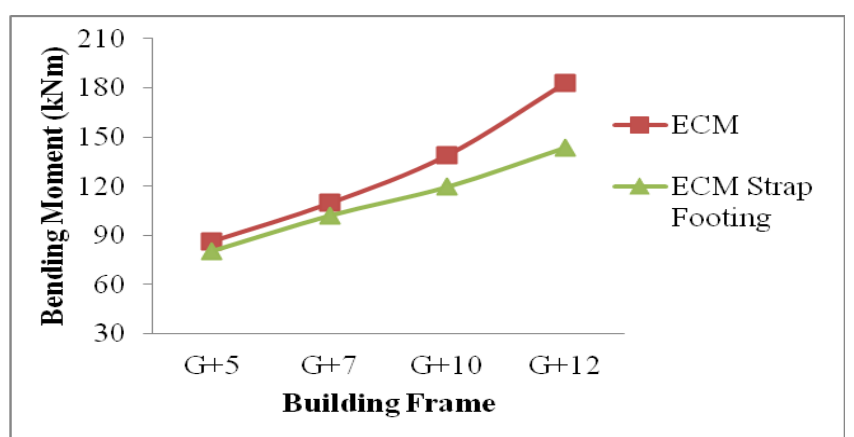

Fig. 12:- Variation of Bending Moment incorporating Strap Footing

From fig no. 12 it is observed that introduction of strap beam at base has reduced the bending moment counterbalancing the SSI effect. For $\mathrm{G}+5, \mathrm{G}+7, \mathrm{G}+10$ and $\mathrm{G}+12$ building frame, the percentage reduction in Bending moment is $10 \%$, $12 \%, 28 \%$ and $55 \%$ respectively with respect to flexible base. Thus it is inferred that strap beam effect is more beneficial for high rise buildings as the percentage decrease is significantly higher as compared to low story buildings.

\subsection{Beam Shear Force:-}

The variations for Beam Shear Force are presented in Figure13.

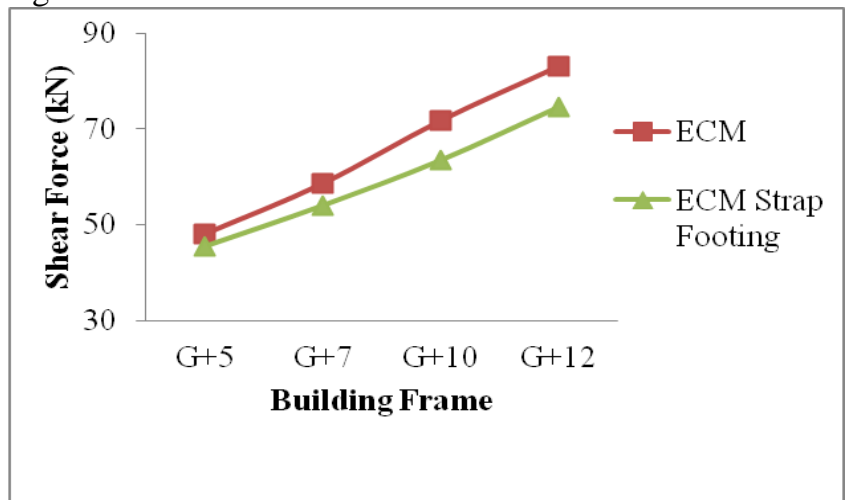

Fig. 13:- Variation of Shear Force incorporating Strap Footing

From fig no.13, it is observed that introduction of strap beam at base has reduced the shear force counterbalancing the SSI effect. It is also observed that for $\mathrm{G}+5$ building frame the percentage decrease is negligible and increases as storey height increases. For $\mathrm{G}+5, \mathrm{G}+7, \mathrm{G}+10$ and $\mathrm{G}+12$ building frame, the percentage reduction in shear force is $7 \%, 12 \%, 20 \%$ and $22 \%$ respectively with respect to flexible base. Thus provision of strap beam observed to be more beneficial for high rise buildings as compared to low rise buildings. 


\section{CONCLUSION:-}

The study is carried out in two parts, in the first part the effectiveness of two SSI model i.e. spring model and elastic continuum model are studied and in the second part effectiveness of strap footing in the elastic continuum model is studied to control the SSI effect. The conclusion based on this study is presented below;

6.1 The natural period of structure increases due to SSI effect. Natural time period is a primary parameter which regulates the seismic lateral response of the building frames. Thus evaluation of this parameter without considering soil structure interaction may cause serious error in seismic design.

6.2 The structural parameters such as beam bending moment, beam shear force, increases due to SSI effect. The percentage increase goes on increasing with high rate for high rise buildings.

6.3 The increase in all the response parameters due to SSI effect is higher in case of Elastic Continuum Model as compared Spring Model. Thus Elastic Continuum Model is more effective than spring model as it considers the whole influenced soil mass beneath the footing which assists in getting realistic behavior of the structure.

6.4 Provision of Strap Footing counterbalances the SSI effect. It is more effective to control the non uniform settlement and rotation of footings due to SSI. Strap footing helps to redistribute forces/moments in the members of the structure.

6.5 Strap beam is observed to be more effective in low rise building to control the seismic parameters such as time period, base shear, roof displacement. Wheras it is observed to be more effective to control the flexural parameters such as beam bending moment and beam shear force

6.6 Thus the overall study reveals that the SSI effect can be effectively controlled by providing strap beams so that base stiffness increases which ensures the stability and performance of structure.

\section{NOTATIONS}

$\mu=$ Poison's Ratio.

$\mathrm{B}=$ Breadth of Foundation.

$\mathrm{G}=$ Shear Modulus of Elasticity.

$\mathrm{K}_{\mathrm{x}}, \mathrm{K}_{\mathrm{y}}, \mathrm{K}_{\mathrm{z}}=$ Stiffness of equivalent soil springs along the translational DOF along $\mathrm{X}, \mathrm{Y}$ and $\mathrm{Z}$ axis.

$\mathrm{K}_{\mathrm{rx}}, \mathrm{K}_{\mathrm{ry}}, \mathrm{K}_{\mathrm{rz}}=$ Stiffness of equivalent rotational soil springs along the rotational DOF along $\mathrm{X}, \mathrm{Y}$ and $\mathrm{Z}$ axis. $\mathrm{L}=$ Length of Foundation.

\section{REFERENCES:-}

[1] Federal Emergency Management Agency Nov 2000.

[2] Sekhar Chandra Dutta, Rana Roy, "A critical review on idealizat3ion and modeling for interaction among soilfoundation structure system", Computers and Structures 80 (2002), pp.1579_1594

[3] Koushik Bhattacharya, Shekhar Chandra Datta, "Assessing lateral period of building frames incorporating soil flexibility", Journal of sound and vibration, 269 (2004), pp.795-821
[4] B.R. Jayalekshmi, "Earthquake response of multistoreyedR.C. Frames with soil structure interaction effects."

[5] VivekGarg, M.S. Hora, "A review on interaction behaviour of structure-foundation-soilsystem.”,International Journal of Engineering Research and Applications,Vol. 2, Issue 6, November- December 2012, pp.639-644

[6] Bowles, J.E.(1998).'Foundation Analysis and design",McGraw Hills, New York.

[7] B.R.Jayalekshmi,

Chandrashekhar.A,

KattaVenkataramana, R.Shivashankar, and Dynamic FEM Analysis of multistoreyed frames including soil foundation structure interaction effects, NITK Research Bulletin Vol.16. No.1, June 2007, p 14 to 18

[8] IS 1893 (Part I): 2002 Criteria for Earthquake Resistant Design of Structures-Generalprovisions and Buildings, Bureau of Indian Standards, New Delhi.

[9] IS 456: 2000 Plain and Reinforced Concrete - Code of practice, Bureau of Indian Standard, New Delhi.

[10] Shiji P.V, Suresh S., Glory Joseph, "Effect of Soil Structure Interaction in Seismic Loads of Framed Structures"; International Journal of Scientific \& Engineering Research Volume 4, Issue 5, May-2013 ISSN 2229-5518.

[11] Brown CB, Laurent JM, Tilton JR. Beam-plate system on winkler foundation. JEngMechDiv ASCE 1977; 103(4): 589-600.

[12] Hetenyi M. A general solution for the bending of beams on elastic foundations of arbitrary continuity. JApplPhys 1950; 21:55-8.

[13] Jenifer Priyankeaetal (2012 ISSN 2250-2459) International Journal of Emerging Technology and Advanced Engineering.

[14] Neelima, B. Pandurangarao, P.Kondana Rama Rao and S.R.K. Reddy (2012 ISSN 2278-0181) Earthquake response of structure under different soil conditions.

[15] Dr.Halkude S.A., Kalyanshetti M.G., Kalyani S.H.: "Soil structure interaction effect on seismic response of R.C. frames with isolated footing"

[16] Dr.Halkude S.A., Kalyanshetti M.G., Barelikar S.M. (2014): "Seismic response of R.C. frames with raft footing considering soil structure interaction" 